\title{
Análise da qualidade da água de chuva e simulação de possíveis impactos ambientais em laboratório: estudo de caso
}

A poluição atmosférica tem aumentado em níveis preocupantes e a chuva ácida é um fator que está atrelado a essa elevação do grau de poluente no ar devido a crescente urbanização que alavancou o surgimento de novas fábricas e aumentou o número de veículos nas cidades, de modo que, atualmente, os níveis de poluentes gerados nos grandes centros variam de 20 a 60 toneladas que vem comprometendo a qualidade do ar, sendo facilmente notáveis nos impactos causados na saúde humana e ao meio ambiente. O presente trabalho visou contribuir com os órgãos ambientais através das análises sobre a qualidade da água de chuva e seus possíveis impactos, tendo como estudo de caso, a incidência no bairro da Boa Vista localizada na cidade do Recife-PE. Foram usados para coletar a água da chuva, recipientes esterilizados e as análises realizadas foram caracterizadas de acordo com a Associação Americana de Saúde Pública - APHA (2012). Analisaramse os seguintes parâmetros nas amostras das águas da chuva: $\mathrm{pH}$, condutividade elétrica, acidez, dureza total, cloreto, sulfato e os metais sódio, potássio, cálcio e magnésio. Também foram realizadas simulações em laboratório a fim de verificar possíveis impactos em estruturas prediais. Os resultados obtidos para a água de chuva coletada em relação a variável pH, no intervalo de setembro de 2017 a junho de 2019, apontam um alto percentual de chuvas consideradas levemente ácida podendo ser um indicativo da elevada concentração de gases emitido pelos veículos e materiais particulados a base de calcário derivado da construção civil. Na simulação da chuva ácida em laboratório foi possível observar o impacto na estrutura a base de concreto com a diminuição na resistência do corpo de prova comprovando que não existe qualquer preocupação na adequação das estruturas das edificações da região estudada quanto ao processo de corrosão causada por possíveis chuvas ácidas.

Palavras-chave: Precipitação; Diagnóstico; pH; Danos.

\section{Analysis of rainwater quality and simulation of possible environmental impacts in the laboratory: case study}

\begin{abstract}
Air pollution has increased at worrying levels and acid rain is a factor that is linked to this increase in the degree of pollutants in the air due to the growing urbanization that has leveraged the emergence of new factories and increased the number of vehicles in cities, so that Currently, the levels of pollutants generated in large cities vary from 20 to 60 tons, which has been compromising air quality, being easily noticeable in the impacts caused on human health and the environment. The present work aimed to contribute with the environmental agencies through the analyzes on the quality of rainwater and its possible impacts, having as a case study, the incidence in the neighborhood of Boa Vista located in the city of Recife-PE. Sterile containers were used to collect rainwater, and the analyzes performed were characterized according to the American Public Health Association - APHA (2012). The following parameters were analyzed in the rainwater samples: $\mathrm{pH}$, electrical conductivity, acidity, total hardness, chloride, sulfate and the metals sodium, potassium, calcium and magnesium. Laboratory simulations were also carried out to verify possible impacts on building structures. The results obtained for the rainwater collected in relation to the $\mathrm{pH}$ variable in the interval from September 2017 to June 2019, point to a high percentage of rains considered slightly acidic and may be an indicator of the high concentration of gases emitted by vehicles and particulate materials the limestone base derived from civil construction. In the simulation of acid rain in the laboratory it was possible to observe the impact on the concrete-based structure with the decrease in the strength of the specimen, proving that there is no concern in the adequacy of the structures of the buildings in the studied region regarding the corrosion process caused by possible acid rain.
\end{abstract}

Keywords: Precipitation; Diagnosis; pH; Damage.

Topic: Engenharia Ambiental

Reviewed anonymously in the process of blind peer

Eduardo Antonio Maia Lins

Instituto Federal de Pernambuco, Brasil http://lattes.cnpq.br/6148771863554184 http://orcid.org/0000-0002-9108-4179

eduardomaialins@gmail.com

Sérgio Carvalho de Paiva (iD

Universidade Católica de Pernambuco, Brasil http://lattes.cnpq.br/4400183060319207 http://orcid.org/0000-0002-0934-7102 sergio.paiva@unicap.br

Letícia Ramos Albuquerque Silva (ic) Universidade Católica de Pernambuco, Brasil http://lattes.cnpq.br/28269285449997126

http://orcid.org/0000-0001-8971-7048 leticia.ramos.a@hotmail.com
Received: 06/04/2021 Approved: 27/04/2021

Raphael Henrique dos Santos Batista (iD Instituto Federal de Pernambuco, Brasil http://lattes.cnpq.br/5310764099162191 http://orcid.org/0000-0002-6727-2508 raphael.santosb38@gmail.com

\section{Referencing this:}

LINS, E. A. M.; PAIVA, S. C.; SILVA, L. R. A.; BATISTA, R. H. S.. Análise da qualidade da água de chuva e simulação de possíveis impactos ambientais em laboratório: estudo de caso. Revista Ibero Americana de Ciências Ambientais, v.12, n.4, p.439-448, 2021. DOI: http://doi.org/10.6008/CBPC2179-6858.2021.004.0034 


\section{INTRODUÇÃO}

A chuva é um fenômeno natural que se dá devido à radiação solar que atinge o solo, fazendo com que a água evapore, e condense em grandes altitudes formando as nuvens. Quando há a saturação das nuvens ocorre à precipitação e esse fato ocorre inúmeras vezes. Por isso, a água da chuva de certa forma tenderia a se assemelhar com a água destilada, sendo livre de impurezas, como íons dissolvidos, e o seu pH tenderia ao ponto neutro. No entanto, tal fato não ocorre em centros urbanos, devido ao alto índice de emissão de gases presente na atmosfera (SOUZA et al., 2016).

A poluição atmosférica tem aumentado em níveis preocupantes e a chuva ácida é um fator que está atrelado a essa elevação do grau de poluente no ar devido a crescente urbanização que alavancou o surgimento de novas fábricas e aumentou o número de veículos nas cidades, de modo que, atualmente, os níveis de poluentes gerados nos grandes centros variam de 20 a 60 toneladas que vem comprometendo a qualidade do ar, sendo facilmente notáveis nos impactos causados na saúde humana e ao meio ambiente (CALLEGARO et al., 2015; SANTOS, 2018).

As precipitações ácidas podem ocorrer por fenômenos naturais ou antropogênicos. As chuvas ácidas naturais são aquelas provocadas por gases, como o dióxido de enxofre, emitidas por processos biológicos que ocorrem nos solos, pântanos e oceanos. Já a precipitação ácida antropogênica é provocada principalmente pela queima de combustíveis fósseis, tais como o carvão e o petróleo que produzem óxidos ácidos poluentes, como o derivado de enxofre (SOx), óxidos nítricos (NOx) e óxidos carbônicos (COx). Em ambos os tipos esses gases reagem com o vapor de água presente na atmosfera, tendo como produtos o ácido sulfúrico $\left(\mathrm{H}_{2} \mathrm{SO}_{4}\right)$ e o ácido nítrico $\left(\mathrm{HNO}_{3}\right)$. Além da queda do $\mathrm{pH}$ dos locais em que se depositam, os locais onde se precipitam sofrem as consequências da ação acidificante da água que provoca corrosões em superfícies metálicas e dissolução de rochas calcárias (CARMO et al., 2018; SOUZA et al., 2016).

As variáveis atmosféricas é um fator determinante na durabilidade dos materiais de construção e, consequentemente, dos edifícios. A chuva ácida por apresentar pH abaixo de 5,6 pode ser responsável pela corrosão de pedra, metal ou tinta. Praticamente todos os materiais se degradam gradualmente quando expostos à chuva e ao vento. A precipitação ácida acelera esse processo, destruindo estátuas, prédios ou monumentos. É importante saber que reparar os estragos causados pela chuva ácida em casas e prédios pode ser extremamente caro, além do mais, muitos monumentos encontram-se já muito degradados e a sua recuperação ou substituição muitas vezes é impossível (SANTOS et al., 2014).

Esse fenômeno vem se intensificando no Brasil, com o aumento do nível industrial e construção de edifícios nos centros urbanos, a emissão de gases veiculares e industriais tem contribuído significativamente para a degradação da qualidade do ar. Assim, pensando nesses centros como grandes fontes de poluentes atmosféricos não existem dados envolvendo os possíveis efeitos da precipitação ácida na região metropolitana do Recife. Porém os estudos brasileiros são praticamente pontuais conforme estudos de Souza et al. (2016), Santos et al. (2017), e Santos (2018) estes autores detectaram a presença de chuva ácida, respectivamente, nos municípios Belém/PA, Rio Claro/SP e Florianópolis/SC relacionando a alteração do pH 
e da condutividade ao crescente nível industrial e a emissão veicular.

O presente trabalho visou contribuir com os órgãos ambientais através das análises sobre a qualidade da água de chuva e seus possíveis impactos, tendo como estudo de caso, a incidência no bairro da Boa Vista localizada na cidade do Recife-PE.

\section{MATERIAIS E MÉTODOS}

\section{Caracterização da área de estudo}

Com finalidade de estudo, o bairro da Boa Vista situado na cidade do Recife, foi selecionado por apresentar características básicas de uma região que pode ser responsável por uma precipitação ácida, como o alto fluxo de veículos. A Boa Vista, Figura 1, onde moram aproximadamente de 20 mil pessoas, em que cerca de 310 mil pessoas transitam essa região e mais de 400 mil veículos trafegam pelo bairro, desses, mais de $50 \%$ são ônibus, o que consideravelmente são os que mais produzem gases poluentes derivados do combustível, assim, para os recifenses pode ser chamado itinerário inevitável para quem circula pela região metropolitana do Recife.

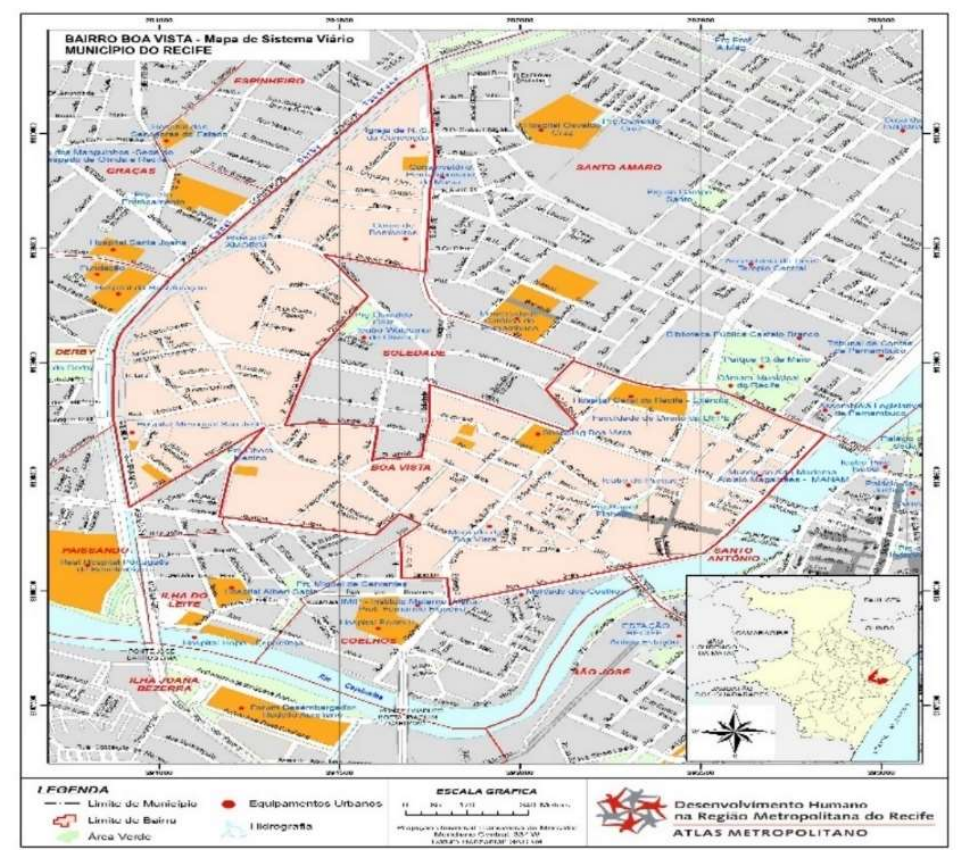

Figura 1: Localização do bairro da Boa vista, Recife-PE. Fonte: IBGE (2010).

\section{Análise de Chuvas Ácidas}

\section{Amostragem da Água da Chuva}

Utilizou-se um método de estudo da área do bairro da Boa Vista a fim de escolher o melhor posicionamento para os pontos de coleta da água da chuva. Essa observação consistiu numa análise envolvendo a massa de veículos, pessoas que circulam a área e o tipo de edificação, que possam ser afetadas pelos efeitos dos fenômenos a serem pesquisados.

Foram usados para coletar a água da chuva, recipientes esterilizados antes de cada coleta. Os recipientes foram colocados em pontos estratégicos da Universidade Católica de Pernambuco situado na Boa 


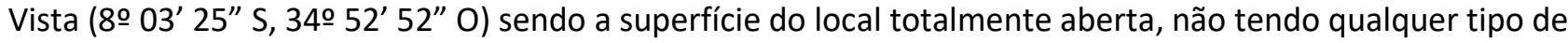
vegetação como árvores, ou próximo de telhados com calhas para que a qualidade da água coletada não fosse influenciada com a introdução de particulados como folhas e pedras de pequeno porte. A coleta foi realizada somente no início da precipitação, não ficando exposta à deposição seca. Obedecendo todos os critérios para coleta de água de chuva da legislação sobre reuso e utilização de água de chuva de acordo com ABNT NBR 15527:2009 modificado para análise de chuva.

\section{Análises Físico-química}

As análises realizadas foram caracterizadas de acordo com a Associação Americana de Saúde Pública - APHA (2012), metodologia padrão para análise de água e águas residuais. Foram analisados os seguintes parâmetros nas amostras das águas da chuva: $\mathrm{pH}$, condutividade elétrica, acidez, dureza total, cloreto, sulfato e os metais sódio, potássio, cálcio e magnésio.

\section{Análise da simulação de corrosão com corpo de prova}

Para verificar as reações da chuva ácida sobre as edificações foram preparados corpos de provas padronizados de concreto para simular o ataque ácido da chuva com traços semelhantes as estruturas da região.

Os corpos de provas foram compostos por um traço de 1:3 (cimento:areia) com relação água/cimento de 0,48. O Cimento utilizado foi o CPII Z 32 RS Nacional, de acordo com a especificação da NBR 5738:2015 foram desenvolvidos no Laboratório de Materiais de Construção Civil da Universidade Católica de Pernambuco, onde após a etapa do tempo de pega do concreto adquirem resistência para serem utilizados simulando uma superfície de edificação. A Figura 2 apresenta a fase do endurecimento do concreto dentro da forma cilíndrica 5/10 para modelagem dos corpos de provas que foram manuseados para o experimento.

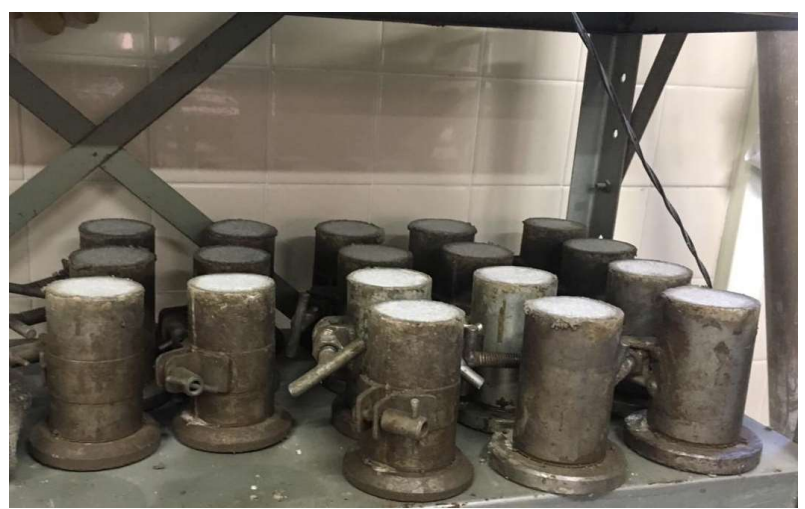

Figura 2: Processo de solidificação do corpo de prova.

Utilizaram-se dois métodos para simular o ataque da chuva ácida no corpo de prova com a finalidade de visualizar através dos resultados dos experimentos os possíveis impactos da precipitação ácida nas superfícies a base de concreto, como nas edificações. No primeiro método, Figura 3, para simulação ácida foi feita soluções de $\mathrm{HCl}$ com pH 4,0; 4,5; 5,0 e 5,5 representando uma faixa que é considerada como chuva ácida pelos autores. Dessa maneira, colocou-se em cada Becker três corpos de provas imersos em cada solução 
ácida e com auxílio de um pHmetro digital estabilizava-se a solução deixando o mais próximo possível do pH respectivo. Assim, a cada 24 horas coletou-se uma alíquota de cada experimento, armazenando-os em recipientes para as análises físico-químicas dos parâmetros de dureza total, cálcio e magnésio, com a finalidade de determinar a resistência do corpo de prova final.

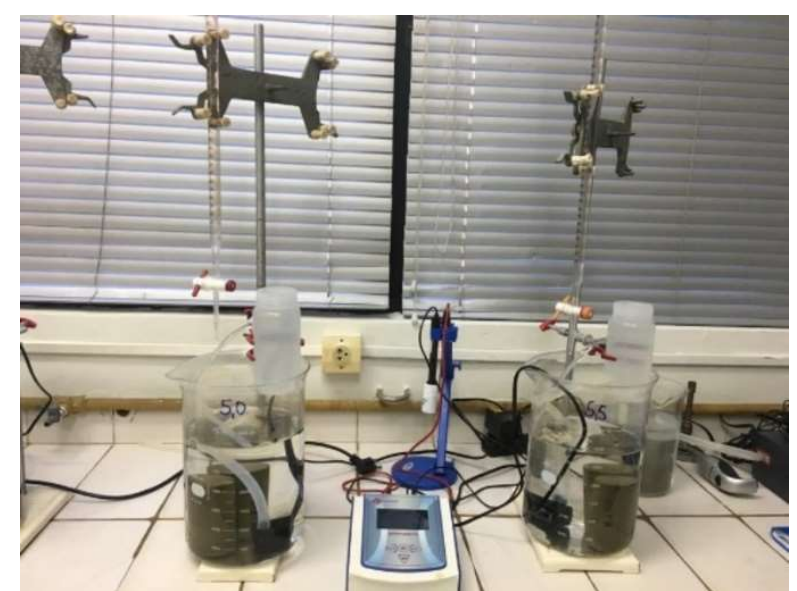

Figura 3: 0 método 1 representa a simulação do ataque da chuva ácida no corpo de prova imersos nas soluções ácidas.

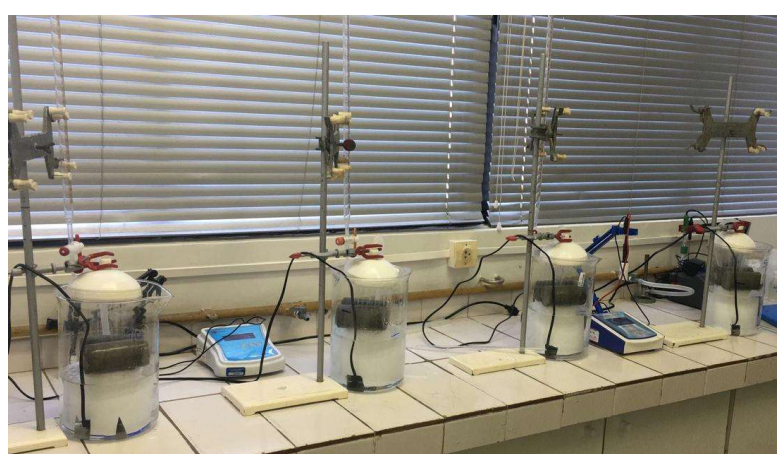

Figura 4: O método 2 representa a simulação do ataque da chuva ácida na superfície do corpo de prova.

Já no segundo método para tornar a simulação de uma chuva mais real como na região, acrescentouse terminais de chuveiro acoplados em garra metálicas nos Becker e conectados a eles mangueira, assim, com o auxílio de bomba d'água bombeou a solução ácida respectiva em todos os pH $(4,0 ; 4,5 ; 5,0$ e 5,5) representando a precipitação da chuva ácida no meio ambiente. Também foram desenvolvidos suportes para os corpos de provas não ficarem imersos na solução ácida, fazendo com que a precipitação simulada tivesse mais contato com a superfície dos corpos de provas. Dessa forma, repetiu-se o mesmo procedimento utilizado no primeiro método para retirada da alíquota e análises físico-química das amostras. A Figura 4 apresenta o segundo método utilizado como estudo no laboratório de físico-química da UNICAP que representa a simulação do ataque da chuva ácida no corpo de prova com auxílio de terminais de chuveiros bombeando as soluções ácidas em contato com a superfície dos corpos de provas.

No final de cada processo os corpos de provas foram retirados da solução e deixados em descanso para secagem, em seguida rotulados de acordo com o pH respectivo, método utilizado e o tempo do experimento. Assim, foram levados para uma empresa de Tecnologia da Construção e Materiais a fim de verificar a resistência no final do experimento e poder concluir se a chuva ácida poderia causar nas superfícies do concreto.

\section{RESULTADOS E DISCUSSÃO}

\section{Análise da Água de Chuva ao Ar Livre}

Foram coletadas amostras da precipitação de chuva em diferentes dias dos meses de agosto 2017 a junho de 2019 na Universidade Católica de Pernambuco, e com isso foram realizadas determinações em triplicata para cada análise dos parâmetros estudados de água da chuva. Assim, também a fim de 
compreender melhor os possíveis impactos que essa chuva pode causar nas edificações, foram feitos corpos de provas para análise do ataque da chuva ácida no concreto.

Como pode observar nos resultados das amostras obtidas na Figura 5, o pH das coletas encontradas nas amostras ficou aproximadamente 6,8, mesmo que essa média seja aceitável, pois segundo diversos autores a chuva na sua normalidade por reagir com o gás carbônico tem uma tendência a acidez com pH em torno de 5,6, isso não está diretamente associado com evidência de acidez nas chuvas, uma vez que dentre as amostras analisadas $48 \%$ delas resultaram no pH levemente ácido que de acordo com Berner et al. (2012), valores de $\mathrm{pH}$ menores que 5,65 resultam em chuva ácida.

A Figura 5 descreve os resultados obtidos da variável pH de acordo com as análises realizadas nas coletas das amostras de água da chuva no intervalo de setembro de 2017 a junho de 2019 que através do histograma representado obtém-se uma margem da variação da acidez apresentada na água da chuva no bairro da Boa Vista, Recife-PE. A região contém alto percentual de chuvas consideradas levemente ácida podendo ser um indicativo da elevada concentração de gases emitido pelos veículos e materiais particulados a base de calcário derivado da construção civil que ao entrar em contato com a água, reduz o pH das amostras, podendo estar afetando a velocidade com o qual os ventos percorrem na região de estudo, como apresentado no 28/01/2019 onde a variação mínima do pH encontrada nas amostras foi de 3,56, concentração bem a baixo das obtidas por Souza et al. (2016) com o valor de 5,84 nas amostras de água de chuva na região Metropolitana de Belém/PA e por Santos (2018) com pH de 4,86 nas amostras de água de chuva coletadas na UFSC em Florianópolis/SC.

$\mathrm{pH}$

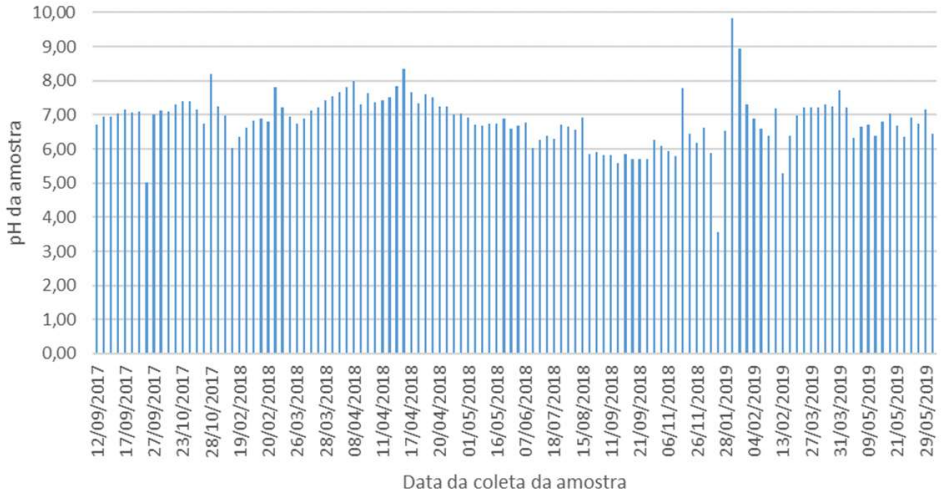

Figura 5: Histograma dos valores de $\mathrm{pH}$ para as amostras de águas de chuva coletadas na região da Boa vista, RecifePE, entre setembro/2017 a Junho/2019.

A Tabela 1 descreve os resultados das análises físico-químicas encontradas nas coletas de água de chuva no bairro da Boa Vista durante o período de agosto de 2017 a junho de 2019 com intuito de determinar possíveis incidências de chuva ácida.

A máxima concentração da condutividade elétrica da água de chuva na Tabela 1 está consideravelmente elevada, provando que há íons dissolvidos que interferiram nas amostras. Este fato evidencia que a condutividade da água da chuva tende a aumentar quando o período de estiagem é maior, como observado na Figura 6, onde esse aumento da condutividade elétrica nas amostras apresentou uma correlação com as partículas vinda da costa litorânea como as concentrações de cloretos e sódio, também a 
cálcio e magnésio que são notados nos resultados de água da chuva. O aumento da condutividade elétrica na água da chuva apresentou correlação com o aumento das espécies iônicas na maioria das amostras, correlação está também citada por Martins (2008).

Tabela 1: Resultados médios das análises físico-químicas das amostras de água de chuva.

\begin{tabular}{llllllllll}
\hline $\begin{array}{c}\text { cond. } \\
(\mathbf{m ~ S})\end{array}$ & \multicolumn{2}{c}{$\begin{array}{c}\text { Dureza Total } \\
(\mathbf{m g} / \mathrm{L})\end{array}$} & $\begin{array}{l}\text { Cálcio } \\
(\mathbf{m g} / \mathbf{L})\end{array}$ & $\begin{array}{l}\text { Magnésio } \\
(\mathbf{m g} / \mathbf{L})\end{array}$ & $\begin{array}{l}\text { Cloreto } \\
(\mathbf{m g} / \mathbf{L})\end{array}$ & $\begin{array}{l}\text { Sulfato } \\
(\mathbf{m g} / \mathbf{L})\end{array}$ & $\begin{array}{l}\text { Sódio } \\
(\mathbf{m g} / \mathbf{L})\end{array}$ & $\begin{array}{l}\text { Potássio } \\
(\mathbf{m g} / \mathbf{L})\end{array}$ \\
\hline Máximo & 416,50 & 280,00 & 146,30 & 61,97 & 185,00 & 21,85 & 52,27 & 20,00 \\
Média & 66,54 & 35,82 & 9,12 & 4,95 & 17,77 & 0,73 & 3,91 & 0,95 \\
Mínimo & 6,14 & 2,00 & 0,80 & 0,24 & 1,00 & 0,00 & 0,30 & 0,05 \\
\hline
\end{tabular}

Notou-se que a água da chuva nesse período não possuiu as características de uma água convencional, pois apresentou a média das condutividades analisadas de $66,54 \mu \mathrm{S}$ e alcançando um valor máximo de até 416,20 $\mu \mathrm{S}$, concentrações bem acima das obtidas por Santos et al. (2017) com o valor de 29,30 $\mu \mathrm{S}$ nas águas de chuva de Rio Claro/SP.

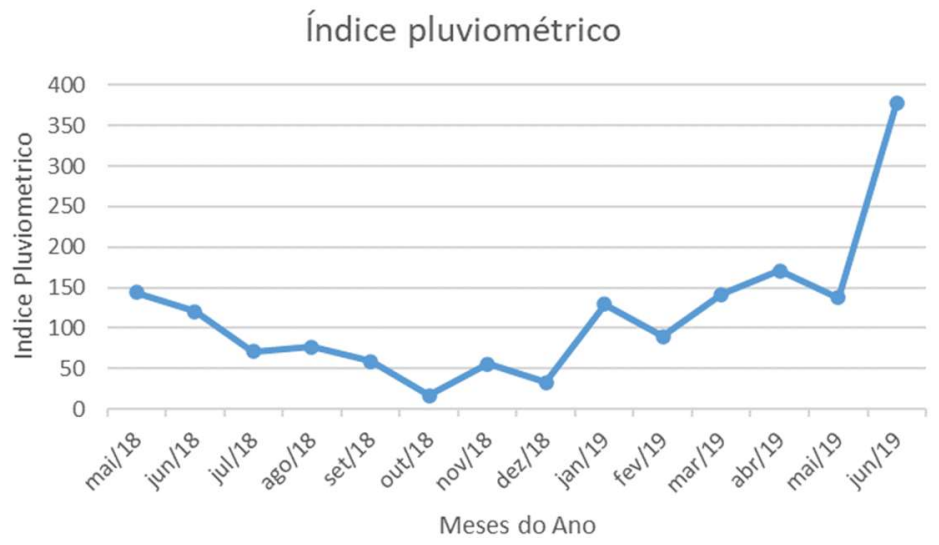

Figura 6: O gráfico descreve o índice pluviométrico da região metropolitana no Recife no período de maio 2018 a junho 2019. Fonte: INMET (2019).

A Figura 6 descreve o índice pluviométrico da precipitação das chuvas na região metropolitana do Recife no último ano de estudo que está diretamente relacionado com os resultados obtidos na Tabela 1, onde se observou uma linearidade do gráfico com o aumento significativo da chuva nos dois últimos meses de 2019, porém com menor intensidade quando comparado aos meses de maio e junho de 2018.

As concentrações dos poluentes da água da chuva foram analisadas na Tabela 1, onde o sulfato

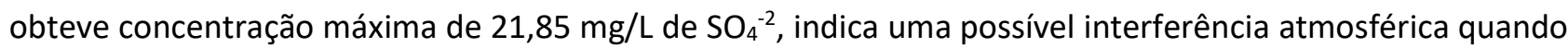
comparada as características originais das águas das chuvas uma vez que nos grandes centros urbanos, normalmente em regiões metropolitanas, a poluição é mais abundante graças a maior concentração de indústrias, ao grande fluxo populacional e veicular. Ressalta-se que alguns poluentes como a presença dos íons sulfato em água de chuva promovem muitos efeitos negativos, dentre eles, a redução da fertilidade do solo devido à liberação de substâncias tóxicas como o alumínio, além do desgaste de materiais da construção civil. Marques et al. (2010) em um trabalho recente cita que o sulfato se destaca na maioria das amostras da água da chuva que eles analisaram.

Assim também, como pode avaliar dentre os metais analisados como cálcio, magnésio, sódio e

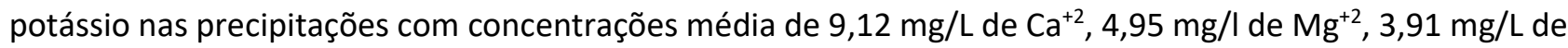


$\mathrm{Na}^{+}$e $0,95 \mathrm{mg} / \mathrm{L}$ de $\mathrm{K}^{+}$há uma maior predominância do íon cálcio em virtude da presença de obras da construção civil no entorno, indicando que pode haver particulados a base de calcário que ao entrar em contato com a água da chuva são solubilizados. Já a alta concentração de magnésio em até $61,97 \mathrm{mg} / \mathrm{L}$ de $\mathrm{Mg}^{+2}$ pode estar relacionada processo antropogênico. Santos et al. (2017) obtiveram valores menores de $\mathrm{SO}_{4}^{-}$ ${ }^{2}\left(0,80 \pm 0,38 \mathrm{mg} \mathrm{L}^{-1}\right), \mathrm{Ca}^{+2}\left(0,68 \pm 0,43 \mathrm{mg} \mathrm{L}^{-1}\right), \mathrm{Na}^{+}\left(0,13 \pm 0,13 \mathrm{mg} \mathrm{L}^{-1}\right), \mathrm{K}+\left(0,42 \pm 0,67 \mathrm{mg} \mathrm{L}^{-1}\right)$ na água da chuva. De acordo com Martins (2008) “os cátions cálcio, magnésio e potássio encontrados em centros urbanos são, em geral, associados à ressuspensão da poeira do solo, bem como às atividades das construções civis".

Portanto, quando essas chuvas são consideradas ácidas degradam os materiais que são compostos de carbonato de cálcio dissolvendo também os monumentos, embora existam diferentes tipos de pedras utilizadas na construção dos edifícios e esculturas, as que são consideradas mais vulneráveis aos ataques a acidez das chuvas são compostas de calcário.

\section{Análise de Possíveis Impactos em Escala de Laboratório}

Com base nesses resultados das análises físico-químicas das águas das chuvas foi feito um comparativo com a água de chuva escoada no laboratório para avaliar um possível impacto nos materiais a base de calcário, como concreto, material muito utilizado na estrutura de edificação. 0 enfoque principal foi na resistência dos corpos de provas, em que são abordadas as propriedades mecânicas, como se aproximando das condições reais empregadas em escala estrutural. O concreto é um tipo de compósito que consiste em um agregado de partículas ligadas umas às outras pela pasta de cimento que apresenta característica porosa na fase hidratada solúvel do cimento (hidróxido de cálcio) por isso torna-se vulnerável quando em contato com a água. Segundo Souza et al. (2016) na análise de degradação dos materiais da construção civil esses compostos sofrem efeitos quando submetidos à ação das variáveis atmosféricas, dentre eles na presença da precipitação ácida.

Dessa forma, a Figura 6 apresenta um histograma com as médias dos resultados do rompimento dos corpos de provas que descreve a resistência do concreto de acordo as análises físico-químicas na simulação de uma chuva ácida escoada no laboratório em solução de pH distintos, indicando uma provável chance de impactos pela precipitação ácida nas edificações.

Como se pode verificar, dentre os dois métodos utilizados aquele em que o corpo de prova apresentou menos resistência após 1032 horas em contato com a simulação da chuva ácida escoada na superfície do concreto (corpo de prova), foi o de pH 4,0, ou seja, pH mais ácido, o que é considerado coerente de acordo com os autores, pois quanto mais ácido for o meio, maior será o arraste dos metais presente na sua composição como de Cálcio, Magnésio, Silício e Alumínio. Assim, fazendo um comparativo com a fase neutra ele tende a diminuir sua resistência em $40,4 \%$ do que na sua composição original. Isso pode ser um dos indicativos da diminuição do tempo de vida útil de muitos edifícios que contêm esse material na sua base de construção e maior será o ataque do ácido sobre o cimento que é alcalino provocando uma despassivação sobre o concreto. 
Resistência do concreto

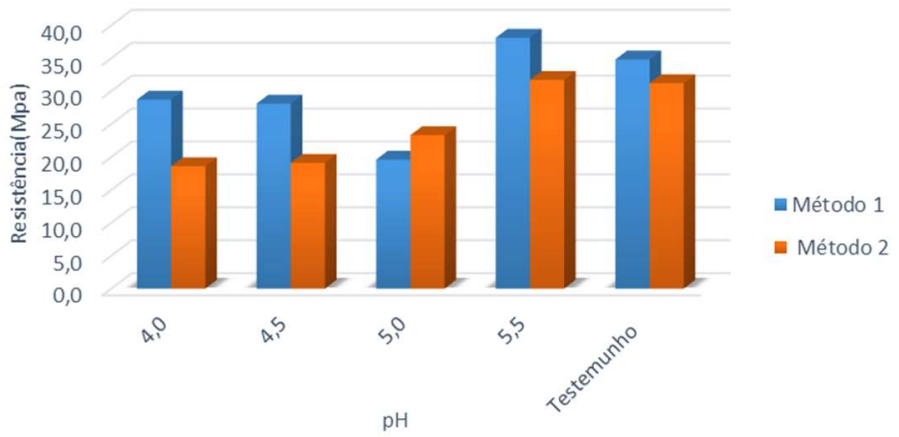

Figura 6: Histograma de descreve as médias dos dois métodos utilizados na simulação do ataque da chuva ácida com a resistência final corpo de prova.

\section{CONCLUSÕES}

As análises físico-químicas realizadas no período do estudo podem indicar a ocorrência da chuva levemente ácida no Bairro da Boa Vista, Recife, Pernambuco. A continuidade das análises físico-químicas em um período mais extenso com a finalidade de possível comprovação de presença de chuvas ácidas torna-se essencial para a pesquisa; O cálcio e magnésio facilmente notados na água de chuva podem estar relacionados provenientes de processos naturais e antropogênicos (construção civil); Notou-se uma alteração significante nos parâmetros analisados nas amostras de água da chuva e essa diferença pode estar relacionada a construção civil e alto fluxo de veículos presentes no bairro estudado; Na simulação da chuva ácida em laboratório foi possível observar o impacto na estrutura a base de concreto com a diminuição na resistência do corpo de prova comprovando que não existe qualquer preocupação na adequação das estruturas das edificações da região estudada quanto ao processo de corrosão causada por possíveis chuvas ácidas.

\section{REFERÊNCIAS}

ABNT. Associação Brasileira de Normas Técnicas. NBR. 5738 (2015). Concreto-Procedimento para moldagem e cura de corpos-de-prova. In: EPCC-ENCONTRO INTERNACIONAL DE PRODUÇÃO CIENTÍFICA UNICESUMAR, 9. Anais. Rio de Janeiro: ABNT, 2015. p.4-8.

ABNT. Associação Brasileira de Normas Técnicas. NBR 15527: água de chuva: aproveitamento em áreas urbanas para fins não potáveis: requisitos. Rio de Janeiro: ABNT, 2009.

APHA. Associação Americana de Saúde Pública. Standard Methods for the Examination of Water and Wastewater. 22 ed. Washington: APHA. 2012.

BERNER, E. K.; BERNER, R. A.. Global environment: water, air, and geochemical cycles. Princeton University Press, 2012.

CALLEGARO, R. M.; ANDRZEJEWSKI, C.; GOMES, D. R.; TURCHETTO, F.; MEZZOMO, J. C.; GRIEBELER, A.. Efeitos da chuva ácida em recursos florestais. Caderno de Pesquisa, v.27, n.3, p.13-20, 2015.

CARMO, A. H. D.; SILVA, E. H. F.; OLIVEIRA, M. G.; SOUZA, G.
R.; BORGES, G. B. C.; VIANNA, C. R.. Os Efeitos da chuva ácida na fertilidade do solo e em cultivares agrícolas. Revista da META, 2018.

IBGE. Instituto Brasileiro de Geografia e Estatística. Resultados do universo: características da população e domicílios. Censo Demográfico. IBGE, 2010.

INMET. Instituto Nacional de Meteorologia. Seção de Observação e Meteorologia Aplicada: Seoma. Dados Metrológicos das precipitações de chuvas na região do Recife do último ano. INMET, 2019.

MARQUES, R.; ZAMPARONI, C. A. G. P.; SILVA, E. C.; MAGALHÃES, A.; GUEDES, S. F.; FORNARO, A.. Composição química de águas de chuva em áreas tropicais e continentais, Cuiabá - MT: Aplicação de Sistema Clima Urbano (S.C.U.). Revista do Departamento de Geografia, v.20, p.63-75, 2010.

MARTINS, R. F.. Avaliação da qualidade das águas de chuva de Florianópolis, Tubarão, Criciúma e São Martinho, com ênfase na caracterização das influências marinhas e continentais simuladas utilizando o modelo HYSPLIT. Dissertação (Mestrado em Engenharia Ambiental) Universidade Federal de Santa Catarina, Florianópolis, 2008. 
SANTOS, E. P. S.; NUNES, D. M.. Chuva ácida: uma problemática contextualizada. Anais do Semex, v.7, n.7, 2014.

SANTOS, O. N.. Avaliação da qualidade da água de chuva do município de Florianópolis/SC. Monografia (Bacharelado) Universidade Federal de Santa Catarina, Florianópolis, 2018.

SANTOS, V.; GASTMANS, D.. Composição química da água de chuva em Rio Claro (SP). Revista do Instituto Geológico, v.37, n.2, p.45-60, 2017.

SOUZA, G.; OLIVEIRA JUNIOR, J. M.; MENDONÇA, N. M.
Chuva ácida: estudo de caso na região metropolitana de Belém/PA. In: SIMPÓSIO DE ESTUDOS E PESQUISAS EM CIÊNCIAS AMBIENTAIS NA AMAZÔNIA, 5. Anais. 2016.

SOUZA, G.; SILVA, R. A.; OLIVEIRA JUNIOR, J. M; MENDONÇA, N. M.. chuva ácida: estudo de caso na região metropolitana de Belém/Pa. 2016.

SOUZA, R. B.; REBOITA, M. S.; WERLE, A. P.; COSTA, E. B. C.. Influência das variáveis atmosféricas na degradação dos materiais da construção civil. REEC-Revista Eletrônica de Engenharia Civil, v.13, n.1, 2016. DOI: https://doi.org/10.5216/reec.v13i1.41448

A CBPC - Companhia Brasileira de Produção Científica (CNPJ: 11.221.422/0001-03) detém os direitos materiais desta publicação. Os direitos referem-se à publicação do trabalho em qualquer parte do mundo, incluindo os direitos às renovações, expansões e disseminações da contribuição, bem como outros direitos subsidiários. Todos os trabalhos publicados eletronicamente poderão posteriormente ser publicados em coletâneas impressas sob coordenação da Sustenere Publishing, da Companhia Brasileira de Produção Científica e seus parceiros autorizados. Os (as) autores (as) preservam os direitos autorais, mas não têm permissão para a publicação da contribuição em outro meio, impresso ou digital, em português ou em tradução. 